\title{
COMPASIÓN Y BIOÉTICA
}

\section{Jimmy Washburn C.*}

Resumen: El dolor humano y los abusos permean la convivencia. Incluso, la eficiencia mediática ha contribuido a que el sufrimiento ajeno entre a los hogares bajo presentaciones espectaculares. La comprensión de la finitud humana y la respuesta bioética que se apareja a ella es el tema que aquí queremos bosquejar. En esta ocasión intentamos establecer relaciones entre la compasión y el principio de beneficencia. Procurar el bienestar de pacientes, extraños en su mayoría, con una actitud, aunada a una percepción de lo ético, que no es objeto de obligación normativa.

Palabras clave: Compasión, bioética, beneficencia

\section{COMPASSION AND BIOETHICS}

\begin{abstract}
Human pain and suffering affect our lives. Moreover, mediatic efficiency has contributed to let foreign suffering enter our homes through spectacular presentations. The subject we want to stress here is comprehension of human finitude and bioethics' response to it. We shall try to establish relationships between compassion and the principle of beneficence. In order to secure patients' wellbeing -strangers most of them- with an attitude and an ethics' perception, that is not object of a normative obligation.
\end{abstract}

Key words: Compassion, bioethics, beneficence

\section{COMPAIX̃̃O E BIOÉTICA}

Resumo: A dor humana e os abusos permeiam a convivência. Inclusive, a eficiência mediatica contribuiu para que o sofrimento alheio entre nos lares sob apresentações espetaculares. A compreensão do fim da vida e a resposta bioética que eqüivale a ela é o tema que queremos esboçar. Nesta ocasião tentamos estabelecer relações entre a compaixão e o principio da beneficiência. Procurar o bem estar de pacientes, estranhos na sua maioria, com uma atitude, aliada a uma percepção do ético, que não é objeto de obrigação normativa.

Palavras-chave: Compaixão, bioética, beneficiência

\section{Introducción}

* Escuela de Filosofía. Universidad de Costa Rica Correspondencia: jimwashie@hotmail.com 
Finitud y compasión, sufrimiento y solidaridad. La ética se ocupa de estas constantes humanas, ya que la convivencia requiera fortalecerse, la vida signifique humanización, la exclusión no sea norma, la existencia valga para ser vivida y no para ser mediatizada. El dolor humano y los abusos permean la convivencia $\mathrm{e}$, incluso, la eficiencia mediática ha contribuido a que el sufrimiento ajeno ingrese a los hogares bajo presentaciones espectaculares. La comprensión de la finitud humana, y la respuesta bioética que se apareja a ella son los temas que aquí queremos bosquejar. La compasión es una respuesta en particular que examinaremos. Aliada con una percepción de lo ético es una actitud controversial: se ha dicho que es un sentimiento, una pasión, una virtud, un mandamiento, que está más allá de la justicia; es una debilidad moral, una forma de egoísmo encubierto, una actitud femenil (como la viera Spinoza), contraria a la "naturaleza" más racional de los hombres. La discusión ha sido abundante y se mantiene en vilo. Además, su significación para las relaciones intersubjetivas no es la misma entre extraños (como es el caso de las relaciones clínicas) que entre cercanos. Aunque las respuestas compasivas pasan por un momento cognitivo -reconocimiento de la desgracia del otro-, pareciera eso fuera insuficiente para justificarlas.

En esta ocasión intentamos establecer relaciones entre la compasión y el principio de beneficencia. Procurar el bienestar de pacientes, extraños en su mayoría, y una actitud, aunada a una percepción de lo ético, que no es objeto de obligación normativa, alguna relación deberían tener. De darse, sería en los términos de una ética mínima -normativa-y una ética máxima.

\section{¿Qué decir de la compasión?}

La reflexión sobre la compasión muestra la relación entre el compasivo y el compadecido, y sus direcciones: ¿qué ve e interpreta cada uno del otro? La definición de sí - quién soy-pasa por la definición del otro -quién es para sí y para mí-, y por medio de ambas se establece la relación. Examinar la relación es notar la dialéctica entre la finitud y el compromiso, cómo se explican mutuamente.

Para el presente ensayo la compasión es entendida como actitud ética inervada por condiciones originarias, como la fragilidad y la finitud(1), a las cuales sobrevienen intuiciones morales a modo de respuestas y sin las cuales hombres y mujeres estarían condenados al dolor y a la muerte en el primer instante de vulnerabilidad. En virtud de esto, a la piedad o compasión se la comprende en virtud de la condición mortal universal de contingencia o finitud que grava la existencia. Estas condiciones rebasan las mediaciones (méritos, diferencias) que embargan las relaciones intersubjetivas. Contenidos éticos mayores que explican las respuestas de benevolencia y $\operatorname{solidaridad}(2)^{1}$, si no para procurar alejar la desgracia y la miseria para que no tengan lugar, sí para alejar la amenaza de muerte. Esta es la esperanza que se deriva de la compasión, en sentido trágico: combatir la fatalidad y salvaguardar la vida humana. El sufrimiento y la desgracia, o el desprecio(3) del otro no son inútiles; la solidaridad y la compasión afloran como respuestas éticas por las cuales la vida de las personas no pierde terreno, antes bien lo recupera y lo asegura. "Como su pena valora todas las demás, la piedad vendría a pregonar que su pena misma da valor a la vida, que las penas valen la vida y que valen tanto más cuanto sabemos compadecerlas (4, p. 247)".

\footnotetext{
"La repetida llamada al antiguo Israel a abrir las puertas a la viuda, al huérfano y al extranjero es una ilustración inicialmente ejemplar de la presión ejercida por el amor sobre la justicia, de forma que puede considerarse un ataque frontal a las prácticas de exclusión que son, quizás, la contrapartida de todo vínculo social fuerte."
} 
Los símbolos dan que pensar, y el texto del Buen Samaritano sugiere elementos relativos al valor de la compasión y su validez ética. Habla de dilemas morales, de compromisos, de estilos de vida, de marginaciones y desprecio, de discernimiento y razón práctica.

La interrogante inicial del texto es por el prójimo: no se sabe quién es. No se le reconoce a simple vista. La parábola responde con la identificación de ese prójimo: aquel que está en desgracia, el que tiene su fragilidad expuesta y no puede solo con ella. Situación típica de los usuarios de los servicios de salud, en mayor o menor grado. Axel Honneth desarrolla sugerencias de E. Bloch en torno a la afirmación de la dignidad a partir de modos de humillación y daño personal. La protección de la integridad es imperativa y se la entiende en virtud de los atentados cometidos contra las personas que minimizan su arraigo y pertenencia a la sociedad y deslegitiman la cultura a la cual aporta y de la cual se nutre(3, pp. 78-79). El prójimo se muestra en su desgracia, en las humillaciones y rebajamientos que las personas sufren $(5, p .109)^{2}$. Cuidado y auxilio coadyuvan a sacar a la persona despreciada de esa anulación y, por ende, se afirma su valor y el compromiso de salvaguardarla, actitud ésta la del samaritano. Los cuidados y auxilio se conjugan para la compasión. Al igual que el infortunio del hombre auxiliado por el samaritano, la experiencia del dolor se torna elocuente y explica el auxilio profesional y afectivo de familiares como también el requerimiento de sentido y valor con miras a la capacidad de resistencia de los pacientes. La interrogante permanente es por la indiferencia ante las experiencias de desequilibrio y resquebrajamiento de las condiciones vitales de los pacientes en nombre de

\footnotetext{
"Todo dolor, incluso el más leve, nos revela nuestra impotencia y nuestra fragilidad, no tan sólo altera la relación del hombre con su cuerpo, sino que invade más allá: contamina la relación total del hombre con su mundo."
}

una objetividad que estima exclusivamente signos y síntomas fisiológicos. ¿Es admisible? Pues no, ya que esta actitud únicamente silencia las experiencias de los pacientes, el significado personal que tiene estar enfermo.

El prójimo es el cercano y fue el samaritano el único que no dio un rodeo cuando lo encontró. En lugar de alejarse, se aproximó, sin familiaridad ni nacionalidad común. Los otros dos hombres lo evitaron, le negaron la proximidad y evitaron compromisos. Se mantuvieron extraños. "La proximidad del otro es [...] el hecho de que el otro no es próximo a mí simplemente en el espacio, o allegado como un pariente, sino que se aproxima esencialmente a mí en tanto yo me siento -en tanto yo soy- responsable de él(6, p. 90)"'. La desgracia tanto diluye como refuerza distancias y extrañezas.

De los márgenes de la sociedad ${ }^{3}$ (el samaritano era un judío impuro) proviene la compasión, que significa atender sus necesidades, levantarlo del suelo y cargar con su existencia que se le torna insoportable y que, metafóricamente, no puede levantar por sus propios medios. Ambos se hacen próximos el uno para el otro. Hablar de las experiencias de despojo o disminución no niega otras situaciones que ameritan conmiseración: el autoengaño, el error, las dependencias, todas experiencias que requieren intervención, discernimiento y deliberación. Tan sólo nos referimos a las experiencias que son semejantes a las clínicas.

La experiencia del desprecio ${ }^{4}$ es común a ambos: una herida causada intersubjetivamente

\footnotetext{
A. Honneth, al hablar de la autocomprensión normativa de las personas, sugiere que “....ello alude a tipos de desprecio personal que causan a un sujeto de manera que quede estructuralmente excluido de la posesión de determinados derechos dentro de una sociedad (p. 81)".

4 El mismo autor entiende el desprecio como "....aquel aspecto de una conducta dañina por el que las personas son heridas en la comprensión positiva de sí mismas que han adquirido por vías intersubjetivas (p. 80)".
} 
a la autocomprensión y a la comprensión de la colectividad. El atropello sufrido es ocasión de rescate y afirmación de la dignidad humana y de los compromisos que de ella se derivan. No presta atención a las diferencias, a los alejamientos que imperan en la sociedad entre una persona y otra. Por encima de esas mediaciones simbólicas, el samaritano responde a las exigencias de la situación, el compadecido reconoce su situación y su contingencia se le muestra. Se ve frágil y cercano a la muerte, pero también ve la mano ajena próxima, única vía para no perder la vida, aun cuando admitir la insuficiencia y la dependencia no es sencillo.

Compadecido y compasivo comparten el desprecio, y la experiencia común establece puentes de comunión, de reafirmación y reconocimiento. Si la ofensa y la marginación son formas de intersubjetividad que destruyen la confianza en sí (la autosuficiencia del hombre en desgracia ha sido invalidada por la expropiación de la cual ha sido objeto) y en el otro (ser asaltado y evadido restan credibilidad a la sociedad en la cual vive); asimismo, estas formas de desprecio se traducen en vías por las cuales reconstruir la dignidad alienada. Una vez más la relación dialéctica entre finitud y compasión. Para el samaritano la diferencia de condiciones se transmuta en aproximación y comunión: hace suyas las desgracias ajenas, las asume como responsabilidad inmediata -el infortunio ajeno apremia(5, pp. 89-96)-. La marginación, la contingencia de la existencia, saberse frágil y mortal, develan una posibilidad de "redención".

Entre los rasgos de racionalidad que pueden indicarse de la misericordia, tenemos la experiencia de la vulneración física y social y, también, la privación de los derechos comunes a la sociedad. Es posible pensar que el prójimo del que se pregunta al comienzo del relato no corresponda con el deber de la ley, y ello justi- fica el rodeo de ambos hombres; mas, ¿por qué esos distingos de personas pueden tener más peso que la desgracia o la miseria humanas? Y ello se arredra más al exigir ese prójimo disminuido una respuesta. ¿La miseria humana (ajena) impone exigencias de auxilio? El amor no es exigible. De acuerdo. Pero de ello no se puede concluir que todas sus derivaciones - la compasión es un caso- no puedan ser mandadas $\mathrm{u}$ obligadas. ¿Qué pasa con los vínculos que dan cohesión a la convivencia? ¿Se agotan en la vida institucional? ¿Será que los extraños morales (Engelhardt) no conciben formas de acercamiento en sus discursos morales como un patrón deseable de vida social?

Experiencia compleja la compasión: el rebajamiento del otro que conmueve al auxilio, la desgracia ajena como potencialmente propia, la condición común que aproxima y, por esta vía, la revelación de los límites de la propia existencia. La respuesta dada al final del relato es una afirmación del reconocimiento: el otro interpela, cuestiona y devela la finitud de la vida humana ${ }^{5}$."Rostro y discurso están ligados. El rostro [del otro] habla. [...] el discurso y, más exactamente, la respuesta o la responsabilidad es esa relación auténtica( $6, p .82)$ ".

El reconocimiento introduce el acercamiento, que no se divisa por las diferencias que mantienen separadas a las personas. Y, posiblemente, ello actuó en el sacerdote y el levita que esquivan al infortunado. El reconocimiento se esboza en las percepciones con que se responde al prójimo, y el texto lo muestra aumentado por el atropello y anulación del que fue objeto

\footnotetext{
Sentirse interpelado y verse obligado son respuestas que dependen de quienes experimentan esas reacciones. Son respuestas deseables, esperables y hasta argumentables: el dolor ajeno es intolerable. Pero siempre es posible que el compromiso no se dé, que no haya una obligación final de respuesta. Por ello optamos por un análisis de la compasión desde condiciones antrópicas que son compartidas por todos. Así como la fragilidad biológica se compensa culturalmente, la fragilidad biográfica remite a la compasión.
} 
el hombre compadecido. Por otra parte, el reconocimiento del otro tiene un efecto o resonancia sobre o para sí mismo -yo soy como el otro- y la comunión, aproximación por encima de las mediaciones de cualquier orden que les distancie. Las pretensiones del compasivo de salvar a la persona desdichada persiguen para sí lo mismo en virtud de una misma condición compartida. "El piadoso o el amante no quieren salvar solamente al otro compadecido o amado, sino salvarse los dos a la vez, no postergan esa salvación a otra vida futura, sino que la buscan empeñadamente en ésta(4, p. 256)". El reconocimiento, con un mismo significado fundamental, corre en ambas direcciones: la existencia humana contingente y las acepciones que se deriven relativas al desprecio vivido por las personas en desgracia $(3, p .86)^{6}$.

La pregunta del relato obtiene respuesta: identifica al prójimo y comprende en qué consiste ser misericordioso. El pasaje de un elemento a otro indica una disposición psicológica; de otra manera el interrogador no hubiera entendido el relato ni hubiera sabido acatar la prescripción. Digamos que hay un paso cognitivo, intuitivo - la parábola, un símbolo, da que pensar- por el cual se justifica el mandato dado al final. Correlativamente, el texto no es explícito en el modo como se aprende la compasión, tan sólo se ordena su práctica. Es el cierre del relato -vete y haz tú lo mismo-, para el que no sabía quién era su prójimo. La identificación del prójimo es un develamiento por medio de la desdicha del sufriente; de otra manera no hubiera sido posible. Su fragilidad recuerda la propia y la misericordia se muestra como compensación y alivio de las heridas su-

\footnotetext{
"De ahí que la relación de reconocimiento que corresponde a esta forma de desprecio sea la que pueda ayudar al individuo a una autoestima de este tipo, una relación de aprobación solidaria para formas de vida alternativas; en esta relación encontrarían los sujetos, con sus características individuales, como personas individualizadas a lo largo de su biografía personal, el reconocimiento recíprocamente alentador."
}

fridas. De lo contrario, la compasión es un sinsentido.

La pregunta inicial del relato despierta una preocupación ética: ¿quién requiere de mí?, autoconfesión ésta de la fragilidad y miseria argumentadas hasta ahora y suponemos que la convivencia de extraños no implica una indiferencia correlativa, aunque es posible. La respuesta apunta a la indicación práctica. La compasión resulta de una interpelación, para la cual basta la desgracia del otro, que es o puede ser la mía; mas pareciera que ello no es evidente, el mal o sufrimiento ajeno no es a priori un móvil ineludible de respuestas. Se hace necesario, entonces, hacerlo conciente, aprender a reconocer al otro en su desdicha y a descubrirla como condición compartida: "a mí también me corresponde". Es éste un momento pedagógico: desarrollar una capacidad para reconocer al prójimo. Es igualmente un momento prescriptivo, agravado por la pretensión de universalización para la vida ética: ¿cómo es posible extenderla a todos los hombres y mujeres? Para responder debemos decir que el reconocimiento del otro es una forma de autocomprensión y de afirmación de la fragilidad de la existencia humana (que es mía y del otro) en demanda de protección y humanización, como aspiración de una forma de vida realmente buena.

Asimismo, la universalización de la compasión sólo sería posible no a partir de una prescripción "ciega", sino del involucramiento de todos los seres humanos en virtud de la fragilidad y miseria originaria que comparten, condición común ineludible que se expresa biográficamente. La apelación a la conciencia de las personas parece el único camino viable, pero no es sencillo; antes bien, es posible pensar que la experiencia juega un peso mayor que la sola prescripción en tanto que "abre los ojos" a aquella realidad que no es evidente. De ahí el papel del símbolo. Sólo en ese momento la compa- 
sión cobra sentido en los términos hasta aquí expuestos. Cuesta no poco darle un correcto estatus racional.

No se nace compasivo, como no se nace virtuoso, ni la razón práctica se da desarrollada de una vez. Ante la desgracia del otro siempre hay un sentimiento de conmiseración que remueve las entrañas. Pero, “...la sensibilización es sólo epidérmica...(7, p. 194)", y la indiferencia fácilmente se alimenta de reacciones emotivas que podrían confabular contra la desgracia de las personas enajenadas. No, no es ésta la compasión a la cual se refiere el texto bíblico ni es esa la prescripción ni el carácter que le acompañan. Bien sea que se considere la compasión una actitud que los individuos desarrollan o una virtud que consistiría en una cualidad humana adquirida, queda en claro que no se posee, aunque puede admitirse una disposición para ella. La adquisición no significa una apropiación "desde fuera" de las personas, a modo de una cualidad que se suma al talante ético, sino que es el resultado de un esfuerzo racional y afectivo. Con el concurso de los demás, se sale de sí mismo. A través del ejercicio de la compasión se llega a ser compasivo y por medio de la compasión se sabe quién es el prójimo. La paradoja reside en el hecho de la desgracia y miseria del otro para su cultivo. "De este hecho resulta claro que ninguna de las virtudes éticas se produce en nosotros por naturaleza, puesto que ninguna cosa que existe por naturaleza se modifica por costumbre $\left(8,1103^{a} 15\right) "$

\section{¿Qué significa la beneficencia para la bioética?}

La bioética es un asunto de sociedades democráticas, liberales y plurales. Y defiende un tipo de relación clínica en la cual el tratamiento de la salud de una persona sea un asunto de corresponsabilidad entre el profesional de la salud y el usuario o paciente. En ese sentido, pues, hay que afirmar que la beneficencia es un móvil del discurso bioético: detener abusos y vejaciones, no tolerar más irrespetos ni manipulaciones. Ante todo, evitar daños y, luego, procurar el bien del otro, así lo estipuló la tradición hipocrática. Los cuidados terapéuticos pasan por las obligaciones para con los pacientes $\mathrm{y}$, en ese sentido, no constituyen la compasión, pero se suman a ella de diversas maneras.

Primum non nocere. Aunque asociado con la no maleficencia (por ejemplo, en el Informe Belmont y las pautas éticas internacionales para la investigación biomédica en la que participan sujetos humanos), la referencia que hacemos se dirige, principalmente, a la beneficencia, es decir, acciones para prevenir daños, eliminar males y promover el bien(9, p. 171). En términos bioéticos, es un principio y se materializa en derechos, diversos según el tipo de relación o situación clínica de que se trate, pero que apuntan a garantizar un bienestar en la salud y la vida. Ningún menoscabo es admisible, ni la existencia de cada quien ha de sufrir expropiación alguna de sus cuerpos. Así, la beneficencia se coloca en lo debido y puja por algo más que se puede hacer por las personas disminuidas(9, p. 172).

En lo que respecta a lo debido, los códigos de moral profesional y la normativa hacen eco de la beneficencia en tanto tipifican modos de bienestar con los que hay obligación: respetar la vida en todas sus manifestaciones, mitigar el dolor, cuidar la salud, fomentar estilos de vida saludable, disponibilidad casi total. En calidad de derechos y deberes, se cuenta con una nutrida normativa que atiende a la generalidad de usuarios así como a poblaciones vulnerables. Estos derechos plantean un patrón de relación clínica por seguir, son una garantía de vida buena colectiva. Por otra parte, el conjunto de derechos se convierte en un telón de fondo contra el cual valorar distintas situaciones específicas, 
como el caso de la investigación clínica en la que participan sujetos humanos, la atención a personas con enfermedades mentales y a discapacitadas, $u$ otras como los dilemas de eutanasia. La beneficencia cuenta con muchas acepciones en virtud de esta normativa, lo cual nos da una descripción variopinta e inagotable.

La bioética se erige como un saber de carácter dialógico(10, pp. 33-42), que ofrece un terreno común a todos los interlocutores de los ambientes clínicos. Imprescindible, por esta vía, deliberar acerca de las posibilidades de bienestar que hay que procurar. Por ser deudora de otros saberes y concepciones de vida buena, la bioética ofrece una orientación $(11-12)^{7}$ a los actores de práctica clínica (profesionales, pacientes y otros). En ese sentido, la búsqueda de bienestar pasa por varios significados: a) la relación clínica no admite fragmentación de la vida y, así, los derechos reflejan aspectos como el trato digno, la confidencialidad, la intimidad. Por otra parte, b) beneficencia significa una relación articulada por obligaciones y demandas, lo cual matiza las asimetrías que caracterizan la relación clínica. Recibir información, dar el consentimiento y colaborar con el tratamiento son algunos de los rasgos apuntados en los derechos que reflejan esto. Asimismo, c) la beneficencia indica que la relación clínica no sirve, únicamente, para diagnosticar, aplicar procedimientos o dar tratamientos. Así, en general, esta relación se debe mover en las conexiones entre la historia individual y colectiva de las personas y el mundo sanitario (vida institucional), entre la subjetividad del paciente y la objetividad de las prácticas clínicas, acotadas por pretensiones de aislamiento de los síntomas y

"Podríamos caracterizarla de mejor manera diciendo que es una instancia de juicio, aunque precisando que se trata de un juicio práctico...(Ladrière, p. 202)". "Es este vaivén entre descripción de los umbrales y apreciación de derechos y deberes, en la zona intermedia entre cosa y persona, el que justifica que clasifiquemos la bioética en la zona del juicio prudencial (P. Ricoeur, 1996, p. 298)". signos mórbidos por medio de procedimientos estandarizados.

Diego Gracia ha insistido, en distintos textos, en que la beneficencia es un principio de obligación imperfecto, junto con la autonomía, ya que ambos son rasgos éticos de la vida de cada individuo $(12, p$. 48) y remiten a la estimación de sí mismo: mi cuerpo y proyecto o plan de vida. Límites que corresponden, de un lado, a lo propio del individuo (ámbito de la excelencia y, por ende, inalienable) y, de otro, al conjunto humano, a la colectividad. La beneficencia es una obligación de cada quien, como también un deber definido profesional e institucionalmente; lleva tanto una carga de subjetividad considerable así como es objeto de intervención pública.

Los mínimos éticos plasmados en derechos no tienen dispensa, son ganancia de la vida democrática que no permite abusos ni descuidos. Tampoco son favores prometidos. Los derechos aquí invocados, y con los cuales se entiende la beneficencia, destacan la participación del paciente en la relación clínica, por lo que los matices biográficos, de profesionales y pacientes, cobran más relieve en los actos clínicos. Piénsese en la intimidad, privacidad y confidencialidad a las cuales tienen derecho los pacientes, y en los relatos de síntomas y exámenes clínicos para estructurar los diagnósticos.

Lo biográfico, las percepciones que se tienen de la vida y de la muerte pasan a ser un insumo de los procedimientos bioéticos, y constituyen un bien que se debe salvaguardar. Lo biográfico, en cuanto estimación de sí, tiene un peso normativo que se plasma en las decisiones que toman las personas. La valoración liberal de la autonomía pasa por la biografía de cada una y no, primeramente, por una condición ontológica. En ese sentido, resulta imposible soslayar la vida de la gente cuando los tratamientos y decisiones la afectan. 
La beneficencia es la vía (bioética) para garantizar la protección de la vida y/o recuperar vidas disminuidas. Tiene lugar, así, la solidaridad y una ampliación de la responsabilidad con quienes sufren desgracias o deterioros. Es un bienestar moldeado por el quehacer profesional -lo que se puede hacer, la capacidad de respuesta- y por la mediación institucional se beneficia según las disposiciones políticas y administrativas, con recursos escasos. Una ética mínima, fundada en principios y normativas como estos, se mueve entre lo suficiente e insuficiente, considera demandas esenciales, pero deja otras por fuera y, en virtud de ello, queda la duda de si la vida no estará -o continúa- en otra parte. Las situaciones o casos clínicos, difíciles o rutinarios, remiten y extienden sus dilemas a las percepciones éticas de sus interlocutores y tocan la convivencia. Razón por la cual se hace necesario argumentar "máximamente" $(14)^{8}$, cuando los mínimos se hacen insuficientes. Algo más allá de lo obligado.

Algunos pensadores han colegido que la beneficencia posee contenidos de compasión y otros ni siquiera la indican. Algunos la ubican más allá de la justicia y, con ello, la sacan del ámbito de estos principios intermedios. El caso más detallado es el de Beauchamp y Childress(15), quienes afirman, a la par de los principios, cinco virtudes, la compasión entre ellas. Sass ha insistido en este carácter de la compasión. Se empareja con la solidaridad y el respeto a la vida. En casos como estos, en que la mención parece marginal y, sin embargo, no lo es, se asocia con una ética de máximos que corre por cuenta de cada persona, supererogatoriamente, en contraste con una ética [aplicada] que es más un asunto público y político(16).

\footnotetext{
Nos interesa mencionar estas contribuciones del Dr. Gracia por cuanto ponen de relieve lo que venimos diciendo de la bioética, su corto alcance y su carácter orientador procedimental. Una ética de máximos, continuación de una ética de mínimos, conecta con la ética vivida por los agentes $\mathrm{y}$ hasta con tradiciones morales pervivientes en la sociedad que se rigen con estimaciones máximas.
}

\section{¿Posee la compasión un lugar dentro del discurso bioético?}

Veíamos, anteriormente, el aporte de la compasión a la teoría ética: una mirada puesta sobre las experiencias biográficas y ligadas con concepciones de vida buena. También indicamos que se alimenta de la fragilidad humana y se articula por la proximidad, reconocimiento y aproximación -dilución de la extrañeza-, la estima de sí y del otro, la interpelación provocada por la desgracia ajena. Estos rasgos son indicadores éticos de una dirección distinta -no opuesta- a la normativa institucional, y las vivencias del desprecio o de la desgracia constituyen un terreno común a todos los individuos. Frágiles y mortales, los seres humanos compartimos esta condición, y de ello se deriva una fuerza prescriptora que obliga a salvar al que está en desgracia. La compasión, hendida en esta experiencia común, es un móvil articulador de la intersubjetividad.

Otras caras indican otras miradas. El desvío de la atención es un descentramiento de la mirada, una distracción por la cual reconocer al otro en desgracia, y descubrir la desgracia y miseria ajenas como mías. Es la mirada que se fija en los lazos intersubjetivos, y la compasión llevada a la clínica es una restauración y mirada perdidas 9 . La beneficencia consistiría en prestar atención a estas realidades, no sólo a lo debido.

No es discutida ni impera en el análisis, pero la compasión es una actitud presente, o ausente, en pacientes y familiares. No es argumentable ni obligatoria, parece que está fuera de lugar, es un asunto de moral privada. No

\footnotetext{
Insistimos en la mirada porque ella está presente en la parábola y, también, en otra línea, la mirada clínica se ha elaborado de una manera que sólo ha puesto atención al cuerpo, a tejidos y órganos, a síntomas y alteraciones fisiológicas, como lo expusiera M. Foucault en "El Nacimiento de la Clínica".
} 
llega a principios, pero los supone, y se sustenta en juicios prácticos (siempre de menor abstracción), asentados en la intuición de la desgracia humana (ponerse en el lugar del otro) y la exigencia de respuesta. Al entrar en relación con otros parámetros éticos, piénsese en los derechos y deberes de pacientes, es necesario buscarle una ubicación en la taxonomía ética.

Ahora bien, la bioética se relaciona, principalmente, con normas y principios éticos, con la regulación de las prácticas profesionales sanitarias y con la protección de la vida de usuarios de los servicios de salud. Ante todo se busca evitar daños adicionales al deterioro vivido; en segundo lugar, procurar el bien del usuario, lo cual pone el acento en lo que cada quien considera como su bienestar. Beneficios generales (trato digno, recibir información, consentimiento informado) se distinguen de beneficios específicos, propios de poblaciones vulnerables y de situaciones altamente críticas (como es el caso de las directivas anticipadas). La acción profesional no admite claudicaciones en cuanto a proporcionar el bienestar demandado. A pesar de ello, queda pendiente un bienestar que no es obligatorio y empata con ideales. ¿Cómo saberlo? Necesariamente las concepciones de lo bueno pasan por las distintas caras de lo ético que acontecen en el medio clínico: enfermos disminuidos, mutilados, con dolor, discapacitados, terminales. Caras de lo humano lejanas de la ficción asociada con la clonación o la medicina restauradora. La beneficencia permite, yendo más allá de lo debido, una localización de lo ético en la existencia-vida, reproducción, muerte, intersubjetividad- como perteneciente a sus sujetos inmediatos y no a otros.

Una ética de máximos: excelencia, traspasar lo debido, dar contenidos específicos. La subjetividad, así reivindicada, cobra relevancia junto a la normativa institucional. Por lo tanto, la compasión pasa a ser parte de la bioética a través de la materialización de intenciones de vida buena por medio de acciones de solidaridad y "rescate", contrarias a la invisibilización de la fragilidad o la fragmentación de la vida(16, p. 20).

La normativa obligatoria para todos se explica por carencias que sufre la convivencia. Los derechos de civiles, y particularmente de pacientes, y toda la normativa bioética se erigen sobre la convivencia entre extraños, obligatoriamente, al estilo de la sociedad hobbesiana. Sin embargo, los acercamientos no se agotan por las disposiciones institucionales, y la jilia aristotélica recuerda los vínculos de cercanía y familiaridad que facilitan la benevolencia y la solidaridad. Pero, ¿qué pasa con los extraños, con los que se relacionan sin vínculo alguno fuera de la carencia o debilidad experimentadas? Pareciera que no puede justificarse la compasión con esas personas sin amistad que la preceda. A lo sumo como una "espontaneidad benévola"(12, p. 198). Sin embargo, hay un apremio, porque el sufrimiento no quede desprotegido ni se escatimen cuidados adicionales. Tampoco se pueden medicalizar las experiencias que pasan los pacientes (desilusión, tristeza, malestar, frustración) por cuanto ello las enajenaría.

La compasión anida en la beneficencia y concede una ampliación de la ética por el reconocimiento positivo de las vidas enajenadas. Por esta vía, más bien, debe entenderse que la compasión mantenga puentes con la normativa. Piénsese en los derechos de las personas adultas mayores y derivaciones complementarias, como la conversación y atenciones no procedimentales. Lo mismo sucede con enfermos terminales o con personas privadas de libertad. No deja de ser paradójico. Lo ético no se nutre de las experiencias positivas, autoimpuestas o no, que no impliquen compro- 
misos significativos con los demás $(3, p .87)^{10}$. Son las experiencias del desprecio y del dolor las que detonan la dimensión ética y abren realidades humanas que permanecen ignotas. $\mathrm{Si}$ la bioética se ocupa, exclusivamente, de los dilemas que se abren con la intervención de la tecnología en los procesos vitales de las personas -nacimiento, muerte, manipulación genética, asignación y distribución de recursos-, pareciera que otros ámbitos de la práctica sanitaria quedan desprotegidos, son considerados como marginales o "ya resueltos" por la deontología imperante. Y la vida de cada quien, ¿dónde queda? Pero esto sólo significaría un desplazamiento de los órdenes de importancia en el terreno de la salud de las personas: ¿apoyan y aseguran los distintos saberes biomédicos los estilos de vida de las personas y, por ende, su calidad? ¿De qué manera se explican la negligencia, la mala práctica y la indiferencia de las que son víctimas las personas sometidas a procesos de curación o rehabilitación? Una vez más la tensión entre lo debido y lo merecido, entre la obligación y la excelencia.

La percepción del organismo humano como una realidad para ser intervenida y manipulada ha conducido a la expropiación de la vida(17, p. 377$)^{11}$, y las decisiones relativas a la vida $\mathrm{y}$ la muerte de las personas se han transferido a otros sujetos. Ello ha contribuido a la fragmentación y al silenciamiento de las experiencias personales. Gadamer había insistido en que la salud y la enfermedad, así como cualquier proceso de curación o rehabilitación no son obra

10 “...no es fuente positiva de motivación, como el altruismo o el respeto, donde la moral puede encontrar un apoyo práctico dentro de la realidad social, sino en la experiencia del desprecio social, experiencia que se presenta espontánea y reiteradamente."

11 "To a great extent, a commitment to wage this battle [to defer death] has driven medicine to develop procedures and technologies that extend how much we can control practically all the aspects of the human body. The medical field has access to body parts that are increasingly mechanical, artificial and replaceable." médica, sino del sujeto que las vive; en él se realizan y cobran sentido, mientras que el médico sólo interactúa con sus pacientes para que la naturaleza haga lo suyo(18). La responsabilidad de la propia existencia (autocuidado, autodeterminación) se convierte en una estrategia para combatir formas de abuso y vejación, para reclamar derechos no reconocidos(3). Lo biográfico y la compasión por la fragilidad, esa presión por conquistar su lugar social, son formas de combatir exclusiones y conquistar la propia subjetividad.

El bienestar puja por rebasar lo obligatorio $\mathrm{y}$, de ese modo, la compasión cobra su lugar. Nunca en oposición con aquel, sino como una continuación; sin derivarse de derechos, tiene sus contenidos específicos, los de cada quien: cuidar, escuchar, mediar, reír, llorar, rezar, soñar juntos, son algunas experiencias, mínimas, con las cuales se puede ilustrar lo que significa la compasión en sitios clínicos. Igualmente con las situaciones más polémicas: pedir la muerte, no tolerar mutilaciones, acompañar los sufrimientos y los deterioros. Nada de ello evita los desenlaces, sólo hace la vida soportable, con sentido.

\section{Conclusiones}

El despojo y la desgracia, al igual que la enfermedad, rebajan la vida humana y desdibujan los vínculos con la sociedad. Esta fragilidad humana permite entender los sitios clínicos como comunidades éticas: procurar el bien de cada paciente es el imperativo que domina en las profesiones sanitarias. Ello redunda en la autopercepción que los pacientes alcanzan: autodeterminación y merecedores de beneficios (bienes, servicios, reconocimiento de derechos, etc.). Sin embargo, no garantiza nada más que lo obligado, y las experiencias nos muestran que compromisos por debajo de lo mínimo se dan cotidianamente. La subjetivi- 
dad de los pacientes sufre al ser fragmentada, expropiada, delineada sin consentimiento. Los mínimos, aun cuando estén garantizados, no son suficientes: ¿cuán protegida y apoyada puede verse una persona en estas situaciones extremas?

Una voz amplia de la bioética debería contemplar que los individuos, efectivamente, recuperen su salud y sepan cuidar de sí mismos, de manera que los deterioros no se den, o bien que puedan manejarlos. Así, la beneficencia y la autonomía no serían únicamente una dirección de la conducta profesional, sino, principalmente, una dimensión de la vida de sus pacientes. Gadamer insiste en que la salud y la enfermedad son, ante todo, una vivencia "subjetiva" $y$, ante ellas, el médico solamente ofrece un "arte" para que el cuerpo mórbido pueda recuperar su ritmo vital $(18, p .15)^{12}$. En ese sentido, frente a la objetividad científica erigida sobre la escisión entre lo valórico y lo fáctico, la subjetividad reivindica su lugar y su peso ético. Habría que pensar, entonces, si la bioética pone atención a este aspecto o solamente es una componenda con un orden médico de cosas que no es humanizador.

La compasión se fija en lo biográfico así como en la intersubjetividad inmediata. Distante de lo normativo. Sin embargo, esta distinción no garantiza nada, sólo la desgracia ajena mueve a la compasión. Pero podría no suceder. Es más cercana a la intuición, y el razonamiento práctico lidia con las conducta obligadas, dispuestas de antemano, las que no pueden dejar de cumplirse. Para llegar a la compasión es necesario seguir el trayecto de la desgracia, de la enfermedad en cualquiera de sus expresiones, de manera que toque fibras profundas. Sólo así se llega a descubrir la existencia humana como una tarea de solidaridad y acompañamiento, no exclusivamente como una realidad por moldear a través de regulaciones.

12 “...toda enfermedad, se apoya en factores imprevisibles, presentes en lo que aún resta de equilibrio. Esta es la razón por la cual la intervención del médico no puede considerarse, en realidad, como un hacer o un producir algo, sino -ante todo- como un refuerzo de los factores que determinan el equilibrio." 


\section{Referencias}

1. Apel K. ¿Es la muerte una condición de posibilidad del significado? Estudios Filosóficos 1992; 117, Vol. XLI: 199-213.

2. Ricoeur P. Pensar la Biblia. Estudios exegéticos y hermenéuticos. Barcelona: Herder; 2001.

3. Honneth A. Integridad y desprecio. Motivos básicos de una concepción de la moral desde la teoría del reconocimiento. Isegoría 1992; 5: 78-92.

4. Arteta A. La compasión. Apología de una virtud bajo sospecha. Barcelona: Paidós Ibérica; 1996.

5. Bustos R. Elementos para una antropología del dolor: el aporte de David Le Breton. Acta Bioethica 2000; 1: 105-11.

6. Lèvinas E. Ética e infinito. Madrid: Visor; 1991.

7. Innerarity D. Ética de la hospitalidad. Barcelona: Península; 2001.

8. Aristóteles. Ética nicomáquea, ética eudemia. Madrid: Gredos; 1986.

9. Camps V. Una vida de calidad. Reflexiones sobre bioética. Barcelona: Ares y Mares. Editorial Crítica; 2002.

10. Lolas F, ed. Bioética y cuidado de la salud. Equidad, calidad, derechos. Santiago de Chile: Programa Regional de Bioética OPS/OMS; 2000.

11. Ladrière J. El sentido de la bioética. Acta Bioethica 2000; 2:197-218.

12. Ricoeur P. Sí mismo como otro. Madrid: Siglo XXI;1996.

13. Gracia D. Bioética clínica. Bogotá: Editorial El Buho; 2000.

14. Gracia D. Calidad y Excelencia en el cuidado de la salud. En: Lolas F, ed. Bioética y Cuidado de la Salud. Equidad, Calidad, Derechos. Santiago de Chile: Programa Regional de Bioética OPS/OMS; 2000: 35-56.

15. Beauchamp T. Childress J. Principles of biomedical ethics. Oxford: Oxford University Press; 2001.

16. Sass H-M: La bioética: fundamentos filosóficos y aplicación. En: Organización Panamericana de la Salud. Bioética: temas y perspectivas. Washington, D.C.: OPS/OMS;1990: 22.

17. Sabatino Ch. Reflections on the Meaning of Care. Nursing Ethics 1999; 6(5): 374-82.

18. Gadamer H-G. El estado oculto de la salud. Barcelona: Editorial Gedisa S.A; 1996. 